\title{
Socio-economic impact of Blockchain utilization on Digital certificates
}

\author{
Untung Rahardja ${ }^{1}$, Qurotul Aini ${ }^{2}$, Frizca Budiarty ${ }^{3}$, Muhamad Yusup ${ }^{4}$, Alwiyah ${ }^{5}$ \\ 1,2Universiti Teknologi Malaysia \\ 3,4University Raharja \\ 5 University Wiraraja Sumenep \\ e-mail: rahardjauntung@graduate.utm.my ${ }^{1}$, qurotul@graduate.utm.my², \\ frizca.budiarty@raharja.info ${ }^{3}$, yusup@raharja.info ${ }^{4}$, alwiyahmahdaliy@yahoo.com5
}

To cite this document :

Rahardja, U., Aini, Q., Budiarty, F., Yusup, M., \& Alwiyah, A. (2021). Socio-economic impact of Blockchain utilization on Digital certificates. Aptisi Transactions on Management (ATM), 5(2), 106-111.

DOI :

https://doi.org/10.33050/atm.v5i2.1508

Abstract
This research is an effective digital certificate publishing activity by utilizing blockchain technology. By implementing decentralized systems and cryptography owned by the blockchain, it will potentially enlarge the educational progress space in Indonesia. The weakness of the current running system, lies in the difficulty of identifying the validity of a certificate issued by an educational institution. Therefore, the advantages that blockchain has, able to assist an educational institution, in establishing a widely accessible certification system infrastructure, to support the transparency and accountability of an educational institution, in identifying the validity of the certificate. Blockcert as one of MIT's tools, while acting as a barometer, is used to perform a series of activities in publishing activities and the implementation of official documents that are designed based on a technology commonly referred to as Blockchain. The research conducted will demonstrate that a decentralized consensus will be able to provide good distribution of information that can include all certificate deployment activities.

Keywords: Blockchain, Socio-economic-certificate, education

\section{Introduction}

Indonesian Government is to establish a development strategy on improving the quality of life of Indonesian society in order to be more evenly and at the same time intended for a level of socio-economic growth is adequate [1]. According to national economic elections, the socioeconomic is concerned about various aspects of life, among others, about being covered with demographics, health, education, housing, criminality, socio-cultural, and household welfare [2]. Indonesia is a country in which most of the population lives in rural areas and only a small part of urban living, this characterizes that Indonesia is an agrarian country that is an agricultural country. It is known that in the Agrarian society where life is still dependent on the production of land as a means of staple production and has a pattern that is homogeneous in the livelihood of a farmer [3]. Education is a conscious effort to donate the ability of human efforts to advance activity. Education as an aspect that contributes human resources intended to increase the knowledge and ability of a person in various activities, is also expected to open an economical way of thinking in the sense of being able to develop the potential that exists to achieve the maximum possible results. Socio-economic reviews of the population include social aspects, socio-cultural aspects, and village aspects related to the institutional and aspect of employment opportunities. The village's economic aspects and job opportunities are closely related to village community welfare issues. The adequacy of food and economic needs for new communities is affordable when their household income is sufficient to cover household and development efforts. [4]. 
Education programs are an improvement in terms of income, productivity, health, nutrition, family life, culture and community participation. Increased revenue and spare parts. Productivity is the economic benefit of society. Improvements in productivity, health, food, family life, culture, and participation are social benefits to the community. For a child to be able to obtain a good education, parents must ensure that their child is not affected when their social condition does not support the achievement of education [5]. Parents should also: the surrounding social environment can be used as a supporter of maximum educational achievement. Families are a major factor in determining the level of people's educational achievement. The technological sophistication of today began to be used, the example of crime mode by utilizing technology as a medium, crime and certificate fraud. In the research done this time to be able to answer how a technological existence that can contribute significantly impacts on the socio-economic [6]. And able to provide solutions to the problem of certificates in the national education sector. Researchers conducted adopting blockchain technology in the empowerment of publishing management as well as improving the authentication of certificates in higher education and to bring a good influence on the socio-economic in Indonesia [7].

\section{Research Method}

This study uses a method that the author will use to obtain the accurate and reliable information that researchers need during the research phase. To solve the problems faced by the author and to achieve the research objectives, there are two (two) research methods, namely:

1. Literature review

2. Blockcert

\subsection{Literature review}

Efforts to improve the certificate authentication system of blockchain technology. Some of the bibliographic studies conducted by the authors aim to determine the theme of previous research, avoid re-creation, determine the methods used in previous studies, and continue to achieve the achievements of previous researchers. In this study used 7 (seven) library studies as research objects and compared to the benchmarks of ongoing research, among others as follows:

1. This research was conducted by Satria Damai Kurnia Hu, et al. in 2019 with the title "Blockchain implementation: E-Voting Case Study" This study discusses an electronic voting system by utilizing Blockchain technology in website-based applications. By utilizing this technology, the voting data that has been done can not be changed, duplicated or deleted. So it can improve the security of voting. In addition, this technology can also keep the confidentiality of the voting parties [10].

2. Quoted from a study conducted in 2016 with the research theme "Blockchain Past Bitcoin". Where Blockchain has great potential for an application and redefines the automated economy. [11].

3. Research conducted in 2018 by An Ebrahimi which discusses the subject of identity services by utilizing blockchain technology that can provide transaction identities between devices by enforcing logic that will generate private hash information values using a hashing algorithm and a hash value signature with a sophisticated signature that uses a generated key. private paired with a public key [12].

4. The research titled "Blockchain based digital certificate provisioning of Internet of things devices" was conducted by JS Callan, et al. in 2019. The research conducted discusses the use of blockchain technology in systems and methods of providing digital certificates to loT devices without the need for a central certification authority [13].

5. Pasquale Forte conducted a study titled "Beyond Bitcoin-Part 1: Critical Research on Blockchain-Based Systems" in 2015. In his research, he discussed blockchain technology that can be used not only for cryptocurrencies, but also for the registration, confirmation and transfer of all types of contracts and properties. Make blockchain technology the main theme in reducing paper activity[14].

6. Steve Huckle conducted a research called "Internet of Things, Blockchain and General Economic Applications" in 2016. In his research it was discussed that blockchain technology can be used to create decentralized economic applications, so that people can make money and safely increase the amount of wealth [15]. 
7. Quaddah has conducted a study conducted in 2017. In this study, it is discussed that blockchain technology is the technology that is expected to be behind Bitcoin. It is interesting to face the challenge of using the consistent management authorization of blockchain technology to regulate device access authorization [16].

In the 7 (seven) library reviews above describes the use of blockchain technology that can be applied in various fields. Blockchain technology itself is a digital-based recording system, and nothing can change that. This creates its own preferences for the blockchain and its users. Therefore, the education sector needs blockchain technology. Blockchain shows that decentralized consensus will provide good distribution of information covering all certificate implementation activities [17].

\subsection{Blockcert}

Blockcert is a barometer that is used to perform a series of activities in publishing activities and the implementation of official documents that are designed based on a technology commonly referred to as Blockchain. Blockcert's purpose was to be an innovation medium in the dissemination of an official privately owned document, recording all activities will be recorded digitally by applying the cryptographic principles present in the Blockchain [18].

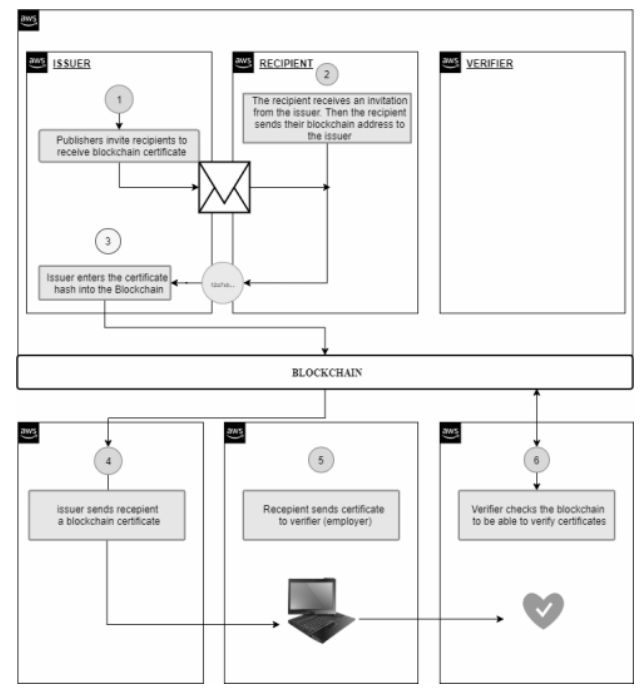

Fig. 1 Blockchert Workflow

(Figure 1) describes Blockcert's workflow. The flow will begin with, the publisher will invite the recipient by email to accept the certificate. Then, the recipient will receive an invitation from the publisher, then the next step the recipient will send the blockchain address to the publisher. This belongs to the unique concept of the blockchain itself. The process is incorporated into blockchain transparency, where a person's identity is encrypted in a complex way through encryption technology represented by a public address. Hidden. The issuer will then characterize the certificate as [19]. An example of a case will be included in the code sha-256 (Secure Hash Algorithm 256), which is an encryption function that is considered the ideal hash function of a special security class in the concept of cryptography. Once hashed, it will enter the send and accept phase, which means the publisher will send the blockchain certificate to the recipient via the address or QR Code recipient that has been given to the publisher. In this way, the recipient will automatically receive the certificate data sent by the issuer [20].

Therefore, the process of receiving data is faster for data verification. then PT will immediately receive certificate data and check data through the blockchain to avoid and eliminate third parties in the process of sending data to the organizer or recipient [21]. The ledger, which is owned by the blockchain, can revolutionize the way data is processed and analyzed. Currently, data is considered money, so all partners will continue to work to solve the problem in order to get quality data [22]. In accordance with the Constitution No. 12 of 2012 that higher education as part of the system national education has a strategic role in educating the life of the nation and 
advance science and technology with pay attention to and apply humanities values as well as the culture and empowerment of the nation sustainable Indonesia [23].

\section{Results and Analysis}

This section shows the certificate printing process currently running at the university prior to blockchain adoption, as well as a description of the blockchain technology certificate authentication system described by the Blockcert method. [24].

\subsection{Problem analysis}

Fake diplomas that are widely circulated in society will of course have a negative and negative impact on the reputation of educational institutions. Because, a diploma can no longer prove a person's ability. This will clearly reduce public interest in formal education. So that these problems greatly affect the socio-economic level, social, cultural and economic inequality will continue to narrow. This is certainly not in line with the vision and mission of the state to become rich and civilize [25]. This research is the first step towards establishing a higher education system more transparent and technologically advanced. This is a higher education credit globally decentralized, and a scoring system that can offer a globally integrated viewpoint for students and higher education institutions, as well as for other potential stakeholders. From a teaching perspective, the aim is to develop useful learning activities Educator teaching can be realized through blockchain technology. Several blockchain applications were introduced in 10 carefully designed studies [26].

\subsection{Troubleshooting}

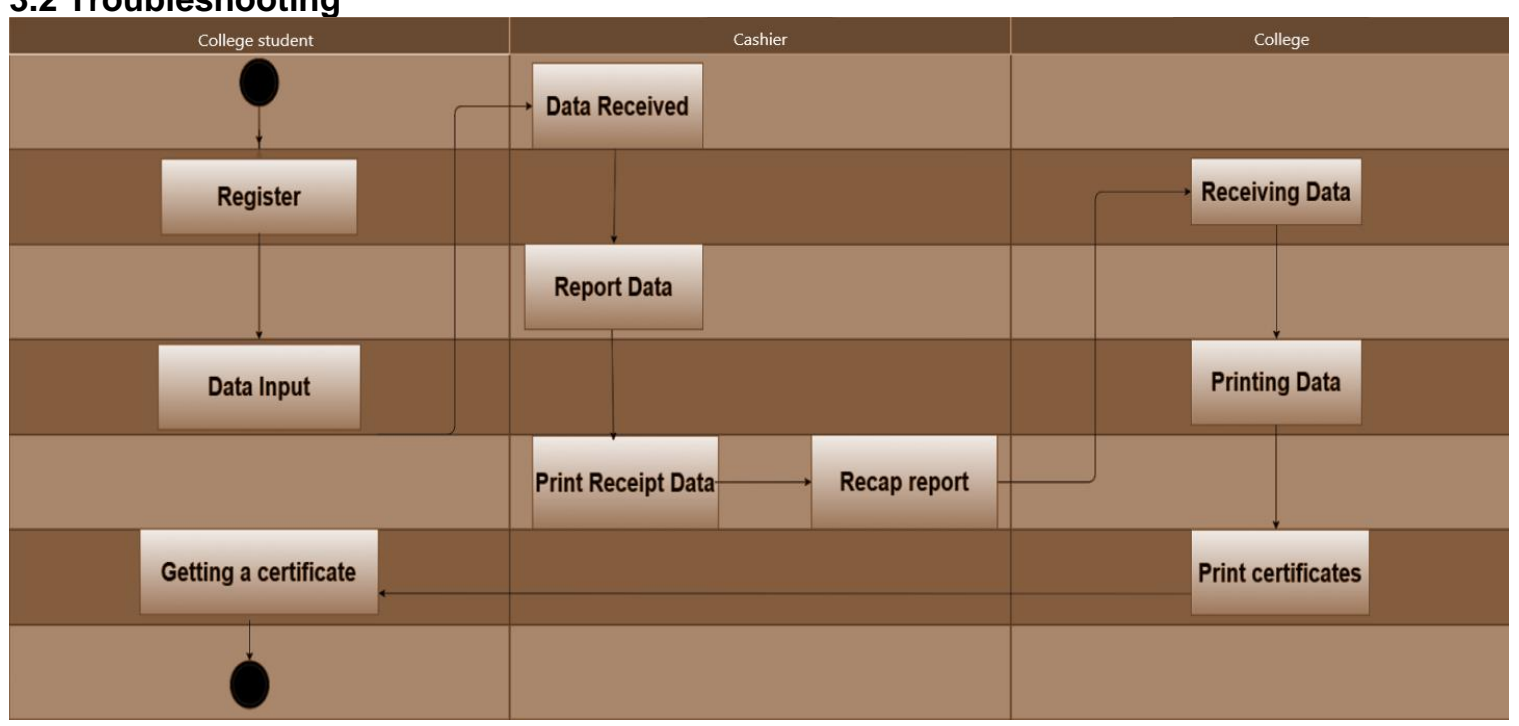

Fig. 2. Current Certificate Printing Flow

There are 10 (Ten) certificate printing threads running before the use of blockchain technology. Starting from the registration of an event conducted by the student, then the student fills his personal data. After the student data is received by the cashier, the cashier will input the data on the report to then make it print the receipts or receipt and the report [27]. Then, the cashier sends the student data to the college, the college receives reports and then checks the accuracy of the data for later in the certificate to print the student. After that, the certificate will be assigned to the student [28]. This process often becomes a delay in granting certificates from an existing time limit. The final stage in which the colleges receive report data from the cashier that still has to manually match. After the matching, it can generate a certificate with the data already obtained [29].

\section{Conclusion}

Blockchain in the world of education today, will certainly bring an impact to be able to contribute success in advancing the national economy and education settings. Its state certificate is considered very important in education, which is the most important role in creating an excellent 
human resources ecosystem [30]. The writing of this article refers to the impact gained significantly in the socio-economic implementation of the blockchain in the certificate issuance system. In e-blockchain-technology certificates that have a certificate of Publication of course have many advantages of the E-Certificate design can clearly be seen, will many have significant benefits by adopting a blockchain in the issuance of certificate activities including the following:

1. Security: The security of certificates resulting from the results of an e-certificate issuance system with the adoption of this blockchain technology, will only be operated by students who have access to public keys.

2. Autonomy: In all the activities undertaken will be recorded throughout the data in a decentralized manner. Which means, on the basis that each node on the blockchain has a track record, it is able to suppress the occurrence of server risk dropped and data loss.

3. Anonymity/Anonymity: In the E-Certificate model used a public key, by storing the private key address in the client's data. It will be widely publicized and the verification process of certificate documents to the agency or regulatory body of the workers will be effective, efficient and able to suppress the amount of costs incurred.

4. Data Integrity: Blockchain is able to maintain and control stored data from data fraud attempts.

The research that has been carried out is expected to have a good impact on the procedures and management systems of publishing and have a substantial impact on the national socio-economy. With the existence of media in the data integrity system that is able to maintain and control the abuse of certificate documents, of course it will be able to contribute to the changes that will be achieved by an educational institution or related organization.

\section{References}

[1] Reuter, T. (2019). German Cultural Diplomacy in Indonesia: Building Cooperation in a Changing World.

[2] Nugraha, A. C. (2020). Penerapan Teknologi Blockchain dalam Lingkungan Pendidikan. Produktif: Jurnal Ilmiah Pendidikan Teknologi Informasi, 4(1), 15-20.

[3] Csikszentmihalyi, M. (2020). Finding flow: The psychology of engagement with everyday life. Hachette UK.

[4] Nurhaeni, T., Handayani, I., Budiarty, F., Apriani, D., \& Sunarya, P. A. (2020, November). Adoption of Upcoming Blockchain Revolution in Higher Education: Its Potential in Validating Certificates. In 2020 Fifth International Conference on Informatics and Computing (ICIC) (pp. 1-5). IEEE.

[5] Yusup, M., Aini, Q., Apriani, D., \& Nursaputri, P. (2019, December). PEMANFAATAN TEKNOLOGI BLOCKCHAIN PADA PROGRAM SERTIFIKASI DOSEN. In SENSITIf: Seminar Nasional Sistem Informasi dan Teknologi Informasi (pp. 365-371).

[6] P. Abas Sunarya, Henderi, Sulistiawati, A. Khoirunisa and P. Nursaputri, "Blockchain Family Deed Certificate for Privacy and Data Security," 2020 Fifth International Conference on Informatics and Computing (ICIC), Gorontalo, Indonesia, 2020, pp. 14, doi: 10.1109/ICIC50835.2020.9288528.

[7] Sunarya, P. A., Aini, Q., Bein, A. S., \& Nursaputri, P. (2019). The Implementation Of Viewboard Of The Head Of Department As A Media For Student Information Is Worth Doing Final Research. ITSDI Journal Edition Vol. 1 No. 1 October 2019, 18.

[8] Aini, Q., Sunarya, P. A., \& Bein, A. S. The Implementation Of Viewboard Of The Head Of Department As A Media For Student Information Is Worth Doing Final Research. IAIC Transactions on Sustainable Digital Innovation, 1(1), 18-25.

[9] Guustaaf, E., Rahardja, U., Aini, Q., Maharani, H., \& Santoso, N. (2020). Blockchainbased Education Project. Aptisi Transactions on Management (ATM), 5(1), 46-61. https://doi.org/https://doi.org/10.33050/atm.v5i1.1433

[10] Andayani, D., Santoso, N. P. L., Khoirunisa, A., \& Pangaribuan, K. (2020). Implementation of the YII Framework-Based Job Training Assessment System. Aptisi Transactions on Management (ATM), 5(1), 1-10.

[11] Febriyanto, E., Rahayu, N., Pangaribuan, K., \& Sunarya, P. A. (2020, October). Using Blockchain Data Security Management for E-Voting Systems. In 2020 8th International Conference on Cyber and IT Service Management (CITSM) (pp. 1-4). IEEE. 
[12] Febriyanto, E., Naufal, R. S., \& Utomo, A. P. P. (2020). SISTEM ABSENSI TERINTEGRASI KURIKULUM 13 BERBASIS R+ PADA SDN SUKANAGARA. Technomedia Journal, 4(2), 186-198.

[13] Bein, A. S., Graha, Y. I., \& Pangestu, A. P. (2020). Pandawan Website Design Based Content Management System As Media E-commerce Transaction. Aptisi Transactions On Technopreneurship (ATT), 2(1), 87-97.

[14] Maulani, G., Rahardja, U., Hardini, M., I'zzaty, R. D., Aini, Q., \& Santoso, N. P. L. (2020, November). Educating Farmers Using Participatory Rural Appraisal Construct. In 2020 Fifth International Conference on Informatics and Computing (ICIC) (pp. 1-8). IEEE.

[15] Sunarya, P. A., Khoirunisa, A., \& Nursaputri, P. (2020, November). Blockchain Family Deed Certificate for Privacy and Data Security. In 2020 Fifth International Conference on Informatics and Computing (ICIC) (pp. 1-4). IEEE.

[16] Yusup, M., Cahvadi, D., Febriyanto, E., \& Budiarty, F. (2020, October). The Impact of Socio-Economic in Digital Signature Using Blockchain Application. In 2020 8th International Conference on Cyber and IT Service Management (CITSM) (pp. 1-6). IEEE.

[17] Lukita, C., Magdalena, L., Rahardja, U., Pranata, S., \& Budiarty, F. (2020). LEDGER MANAGEMENT INFORMATION SYSTEM FOR NATIONAL SPORT COMMITTEE OF INDONESIA. PalArch's Journal of Archaeology of Egypt/Egyptology, 17(6), 322-338.

[18] Febriyanto, E., \& Naufal, R. S. (2019). Attitude Competency Assessment in the 2013 Curriculum Based On Elementary School Prototyping Methods. IAIC Transactions on Sustainable Digital Innovation, 1(1), 87-96.

[19] Underwood, S. (2016). Blockchain beyond bitcoin.

[20] Forte, P., Romano, D., \& Schmid, G. (2015). Beyond Bitcoin-Part I: A critical look at blockchain-based systems. IACR Cryptology ePrint Archive, 2015, 1164

[21] Qurotul, Aini. (2019). Understanding How Gamification Influences Behaviour in Education. International Journal of Advanced Trends in Computer Science and Engineering.

[22] Rahardja, U., Harahap, E. P., \& Dewi, S. R. (2019). The strategy of enhancing article citation and $\mathrm{H}$-index on SINTA to improve tertiary reputation. TELKOMNIKA, 17(2), 683-692

[23] Dinh, T. T. A., Wang, J., Chen, G., Liu, R., Ooi, B. C., \& Tan, K. L. (2017, May). Blockbench: A framework for analyzing private blockchains. In Proceedings of the 2017 ACM International Conference on Management of Data (pp. 1085-1100).

[24] Nakamoto, S. (2019). Bitcoin: A peer-to-peer electronic cash system. Manubot.

[25] Arief, L., \& Sundara, T. A. (2017). Studi atas Pemanfaatan Blockchain bagi Internet of Things (loT). Jurnal Rekayasa Sistem dan Teknologi Informasi, 1(1).

[26] Andayani, D., Santoso, N. P. L., Khoirunisa, A., \& Pangaribuan, K. (2021). Implementation of the YII Framework-Based Job Training Assessment System. Aptisi Transactions on Management (ATM), 5(1), 1-10.

[27] Depiana, E., \& Hartelina, H. (2021). Marketing Service on Customer Satisfaction of Yamaha Motorcycles at PT Ramarayo Perdana Karawang. Aptisi Transactions on Management (ATM), 5(1), 11-19.

[28] Setyowati, W., Kurniawan, P. C., Mardiansyah, A., Harahap, E. P., \& Lutfiani, N. (2021). The Role Of Duty Complexity As A Moderation Of The Influence Auditor's Professional Knowledge And Ethics On Audit Quality. Aptisi Transactions on Management (ATM), 5(1), 20-29.

[29] Hasiany, D. D., Ahman, E., Suwatno, S., \& Santoso, B. (2021). Implementation of Management Performance: SAKIP In Strengthening Bureaucratic Reform (Research on PPPPTK TK and PLB). Aptisi Transactions on Management (ATM), 5(1), 30-45.

[30] Guustaaf, E., Rahardja, U., Aini, Q., Maharani, H. W., \& Santoso, N. A. (2021). Blockchain-based Education Project. Aptisi Transactions on Management (ATM), 5(1), 46-61. 